\title{
Advanced Research on cis-Neonicotinoids
}

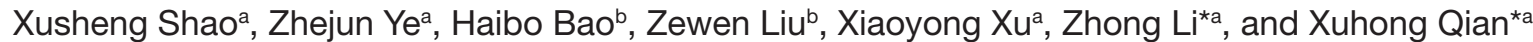

\begin{abstract}
Neonicotinoids are a type of neonicotinoid, in which the nitro or the cyano group are in cis-configuration relative to heteroaromatic moiety, which show excellent activities against a range of insect species. This review covers cis-neonicotinoids with commercialization perspectives, structural optimization (phenylazoneonicotinoids and chlorothiazolyl analogues of Paichongding), modes of action studies, radiao-synthesis of Paichongding and Cycloxaprid, and photostability of neonicotinoids.
\end{abstract}

Keywords: Activity · Insecticide $\cdot$ cis-Neonicotinoids

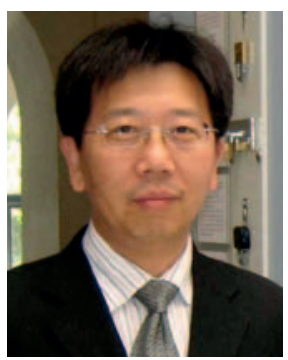

Xuhong Qian, born in Jiangsu, in 1962, received his B.S., M.S. and Ph.D. degrees from East China Institute of Chemical Technology in 1982, 1985 and 1988, respectively. Then he was associate researcher in Lamar University, US and A. v. Humboldt postdoctoral fellow in Wuerzburg University, West Germany (1989-1991), he returned and became associate professor (1992) and professor (1995-2000, 2004-present) in his Alma Mater, presently named, East China University of Science and Technology. During the period 2000-2004, he was Chongkong professor in Dalian University of Technology. His research interests cover aspects of bioorganic chemistry \& engineering related to dyes and pesticides, e.g. fluorescent sensors and antitumor agents derived from dyes, as well as of green insecticides and insect-growthing regulators.

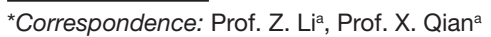
aEast China University of Science and Technology Shanghai Key Laboratory of Chemical Biology, School of Pharmacy

130 Meilong Road

200237 Shanghai, China

Tel.: +86 2164253984

Fax: +862164252603

E-mail: lizhong@ecust.edu.cn, xhqian@ecust.edu.cn

${ }^{b}$ Key Laboratory of Monitoring and Management of Plant Disease and Insect

Ministry of Agriculture, College of Plant Protection

Nanjing Agricultural University

Tongwei Road 6, Nanjing 210095, China
}

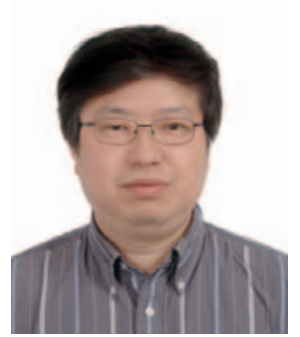

Zhong Li, born in Jiangsu, in 1968, received his B.S., M.S. and Ph.D. degrees from East China University of Science and Technology in 1990, 1993 and 1996, respectively. From 1999 to 2001, he worked as ITIT and AIST postdoctoral fellow in National Institute of Materials and Chemical Research in Tukuba, Japan. Then he returned to East China University of Science and Technology, and became full professor in 2003. His research interest is in pesticide chemistry, e.g. neonicotinoid insecticides, insect growth regulator, and 2D and 3D-QSAR study of bioactivity compounds.

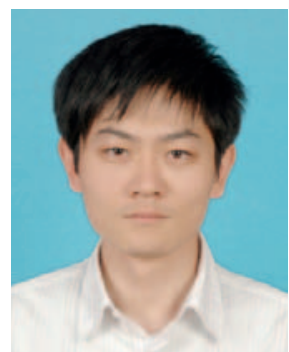

Xusheng Shao, born in Shandong, in 1980, received his B.S. degree from Jinan University in 2003 and his Ph.D. degrees from East China University of Science and Technology (ECUST) in 2009. From 2009 to present, he is an lecture in ECUST. His research interests focus on pesticide chemistry, such as neonicotinoids, insecticides acting on ryanodine receptors, insect growth regulators.

\section{Introduction}

The nicotinic acetylcholine receptor (nAChR), one of the most important insecticidal targets, ${ }^{[1,2]}$ plays a crucial role in mediating rapid excitatory neurotransmission in the insect central nervous system(CNS). ${ }^{[3-5]}$ In the past three decades, the discovery of imidacloprid was regarded as a milestone in insecticide research, ${ }^{6]}$ leading to the fast growth and systematic insight into the neonicotinoid insecticides. As the inventor of imidacloprid, Shinzo Kagabu received the 2010 American Chemical Society International Award. ${ }^{[7]}$ Today, the neonicotinoid family has successful established its place in crop protection and pet hygiene, ${ }^{[8-10]}$ holding the biggest share of the insecticidal market (US \$ 2.632 billion in 2009). [3,11] Acting as a selective insecticide on the agonist site of the nAChRs, neonicotinoids present high insecticidal potency and supreme systematic properties in piercing-sucking insects with the characteristic of low toxicity, no cross-resistance, unique mode of action, and safe to mammals and wildlife. ${ }^{[12]}$ The recently reported compound Sulfoxaflor was the prelude to the fourth generation of neonicotinoid development, which potentially accounts for a market share of over US \$ 400 million. ${ }^{[13,14]}$

The obvious need to tackle resistance and bee toxicity has prompted continued exploration of new neonicotinoid molecules. Focusing on this purpose, the authors' group performed detailed studies on cis-neonicotinoids. Fortunately, three novel neonicotinoids Paichongding, IPPA152201 and Cycloxaprid (Fig. 1) with less cross-resistance in strains of the brown planthopper were discovered. Considering the authors' recent research results in this field, a review paper on cis-neonicotinoids has been presented in Journal of Agricultural and Food Chemistry which mainly focused on the molecular design strategies and bioactivities. ${ }^{[15]}$ One year 
later, as a follow-up, we present herein our recent related research on cis-neonicotinoids. Although this research might not seem directly related, it is all part of our project on cis-neonicotinoids.

\section{2. cis-Neonicotinoids with Commercialization Perspectives}

Paichongding, IPPA152201 and Cycloxaprid are three cis-neonicotinoids in line for commercialization in China. Paichongding was jointly developed with Jiangsu Kwin Co., Ltd. Paichongding has obtained a temporary pesticide registration, and a $10 \%$ suspension has been sold on the Chinese market. Although IPPA152201 has extremely excellent activities, development as an insecticide was impeded by its weak stability. Fortunately, it was found that IPPA152201 exhibited excellent activity on Taeniae and Coccidia by either injection or oral application, which could lead to its development as a veterinary drug. This case demonstrates that it can be difficult to predict exactly what can happen during pesticide discovery. Produced by Shanghai Shengnong Pesticides Co., Ltd, Cycloxaprid is expected to acquire temporary pesticide registration and be launched in China in 2013. All three compounds show excellent activities against a variety of insects, such as Nephotettix bipunctatus, Laodelphasx cstriatellus, Nilaparvata lugens, Myzus persicae, Frankliniella occidentalis, Bemisia argentifolii, and Aphis craccivora. In addition to outstanding activity against homoptera insects, IPPA152201 also has high activities against lepidoptera insects, such as Pseudaletia separate Walker and Cnaphalocrocis medinalis Guenee (unpublished results). They also exhibit better bioactivity against imidacloprid-resistant insects. For instance, Paichongding,
IPPA152201 and cycloxaprid displayed two-fold, 30-fold and 50-fold higher activity against imidacloprid-resistant strains of the brown planthopper (Nilaparvata lugens), respectively. ${ }^{[16-18]}$ Meanwhile, they show low mammalian toxicity and are considered safe for birds, fish and bees. The synthetic routes of these three compounds can be easily industrialized, starting from the nitromethylene analogue of imidacloprid (6-Cl-PMNI). 6-Cl-PMNI, a cyclic $\beta$-nitroenamine with two reactive nucleophilic sites, is a good precursor and lead compound for further modification (Scheme 1). Reaction of 6-Cl-PMNI with crotonaldehyde and subsequent etherification by 1-propanol afford Paichongding. IPPA152201 is generated from the reaction of 6-Cl-PMNI with furfural catalyzed by concentrated hydrochloric acid in acetonitrile, while Cycloxaprid was synthesized from 6-Cl-PMNI and succinaldehyde under the same reaction conditions as IPPA152201.[16-18]

\section{Further Structural Modification of cis-Neonicotinoids}

\subsection{Phenylazoneonicotinoids based on $\pi-\pi$ Stacking Interactions}

The progress in uncovering modes of action, especially through the acquisition of high-resolution crystal structures of AChBP-neonicotinoid complexes promoted receptor structure-guided neonicotinoid design. ${ }^{[19-21]}$ Recently, an alternative binding model was also proposed by our group. In this novel model, the hydrogen bonds between neonicotinoids and the positively charged side chains of Arg/Lys play essential roles in the binding. Moreover, the cooperative $\pi-\pi$ interaction between analogues and the indole ring also contributes to the binding, which exerts great influence on the

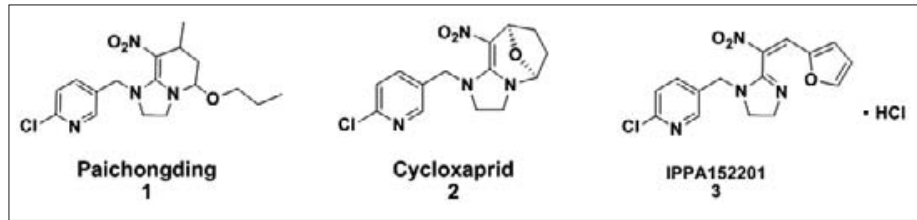

Fig. 1. Paichongding, Cycloxaprid and IPPA152201 with commercial perspectives in China.

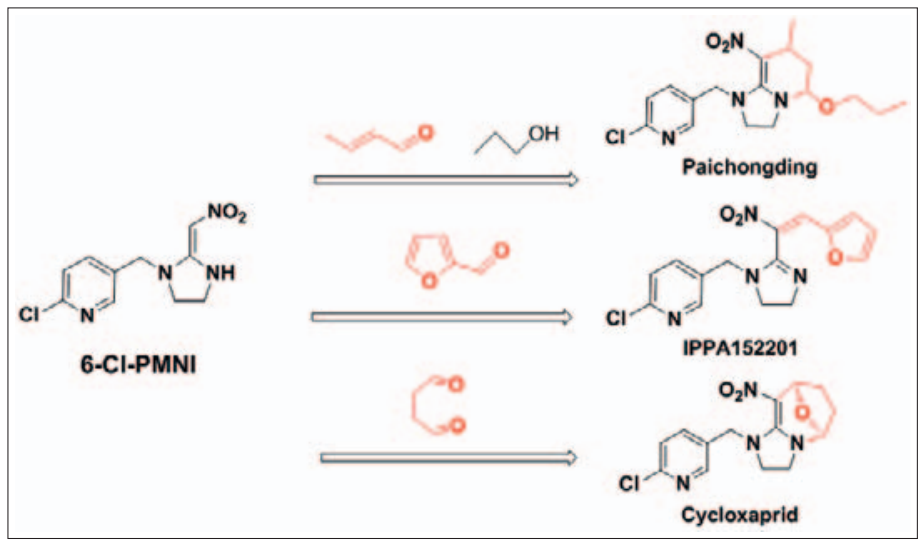

strength of the hydrogen bond to Arg and then affects the activity and selectivity of neonicotinoids. ${ }^{[22]}$ This model implies that the enhancement of the $\pi-\pi$ interaction might strengthen the binding interaction with the receptor, which would eventually influence the insecticidal activity. Based on the point above, neonicotinoids with a nitro-conjugated system and some 1,4-dihydropyridine analogues have been developed in our lab (Scheme 2).[23,24] All these novel neonicotinoid candidates with enhanced $\pi-\pi$ interaction displayed excellent insecticidal activities. These observations proved that enhancing the $\pi-\pi$ interaction was a feasible way for novel neonicotinoid molecule design. To further promote the $\pi-\pi$ interaction between molecule and amino acid residues, a series of phenylazoneonicotinoids were designed and synthesized. ${ }^{[25]}$ The phenylazoneonicotinoids were obtained by the reaction of 6-Cl-PMNI with diazonium salts prepared from anilines in acetone at $0{ }^{\circ} \mathrm{C}$. To our delight, some compounds with much higher activity against cowpea aphids (Aphis craccivora) were obtained. The $\mathrm{LC}_{50}$ of $\mathbf{3}$ was $0.0028 \mathrm{mmol} \mathrm{L}^{-1}$, 12-fold higher than that of imidacloprid $\left(\mathrm{LC}_{50}=0.03502 \mathrm{mmol} \mathrm{L}^{-1}\right)$. Interesting structure-activity relationships (SAR) were revealed, in which tiny differences in substituents resulted in dramatically different configurations and large variations in bioactivity. SAR showed that electron-donating groups on positions 2 and 6 of the phenyl ring were extremely vital to high insecticidal activity.

\subsection{Chlorothiazolyl Analogues of Paichongding}

The discovery of second-generation neonicotinoids (thiamethoxam and clothianidin) made it clear that the chlorothiazolyl skeleton was an effective bioisostere of chloropyridyl in neonicotinoid molecular design. [26] Continued structural optimization of neonicotinoids with tetrahydropyridinefixed cis-configuration (Paichongding analogues) resulted in the synthesis of a series of chlorothiazolyl analogues (Scheme 3).[27] Some chlorothiazolyl analogues exhibited good activity against cowpea aphis. The structureactivity relationships associated with chlorothiazolyl analogues were consistent with that of the chloropyridyl analogues, indicating that chlorothiazolyl moiety was an effective replacement for chloropyridyl.

\section{Preliminary Research on Mechanism or Modes of Action of cis-Neonicotinoids}

The identification of modes of action could help us understand how 


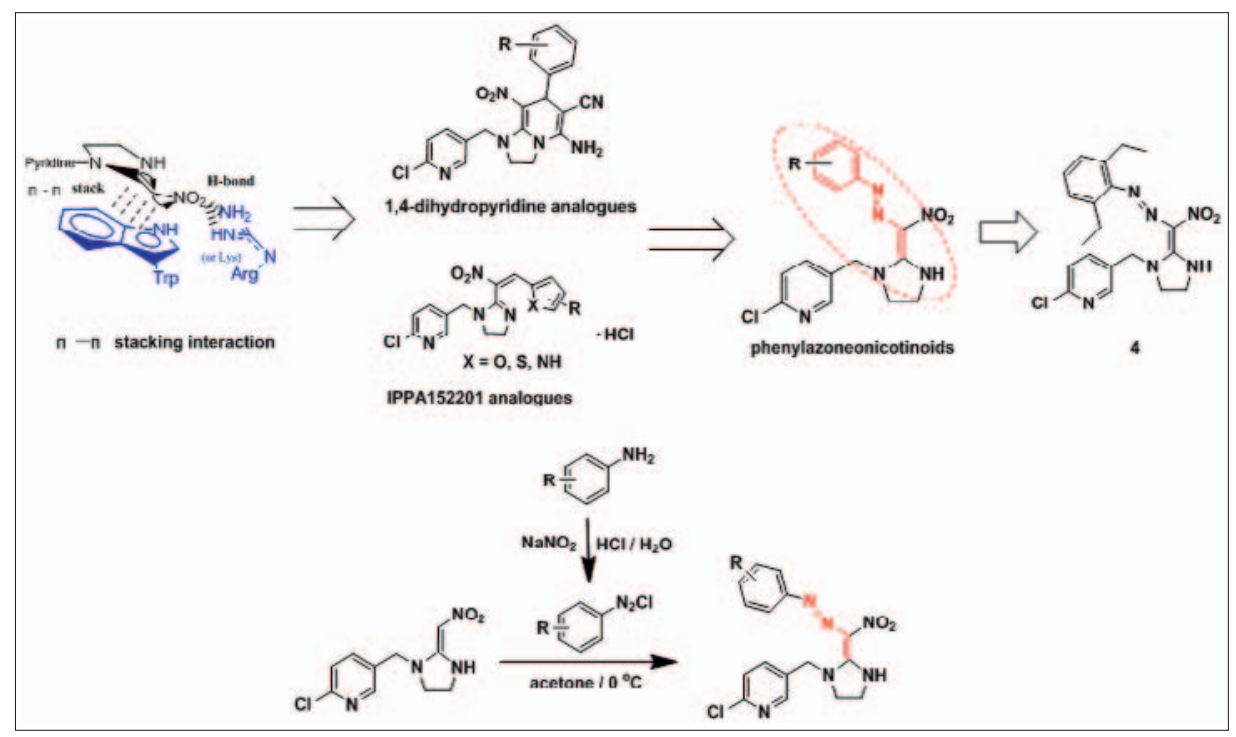

Scheme 2. Design and synthesis of phenylazoneonicotinoids based on $\pi-\pi$ stacking interaction.

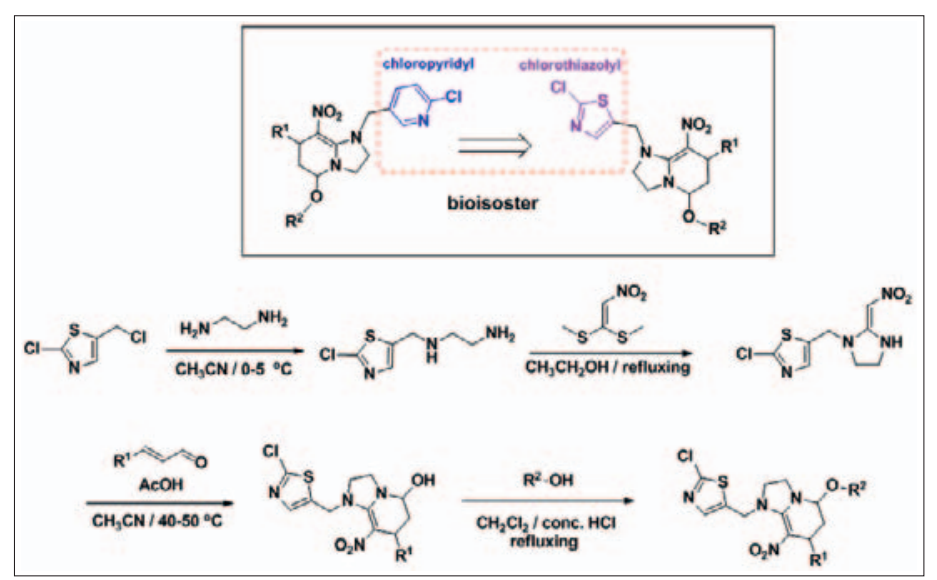

Scheme 3. Design and synthesis of chlorothiazolyl analogues of Paichongding. are well established and the crystal structures of AChBP-trans-neonicotinoids have also been obtained. ${ }^{[28-30]}$ The unique cis-configuration pharmacophore may involve a differential interaction with nAChRs. Therefore, the preliminary interaction situation of three representative cis-neonicotinoids, Paichongding, IPPA152201 and Cycloxaprid were studied. Paichongding interacts with nAChRs in the brown planthopper (Nilaparvata lugens) as an agonist. However, it discriminates between the high and low affinity imidacloprid binding sites. Imidacloprid has two binding sites with different affinities, while Paichongding acts preferentially at the high affinity imidacloprid binding site in the $N$. lugens membranes. ${ }^{[31]}$ IPPA152201 is also an agonist on nAChRs. It has high affinity with nAChRs in cockroach or brown planthopper, which is similar to imidacloprid. Both Paichongding and IPPA152201 are influenced by the Y151S mutation in Nla1 to some extent. ${ }^{[32]}$ Preliminary research on Cycloxaprid showed that it acts on nAChRs as an antagonist at certain dosages (unpublished work); detailed studies are still in progress.

\section{Radiosynthesis of Paichongding and Cycloxaprid}

To elucidate the MOA, metabolism, degradation and environmental behavior in detail, tritium-labeled Paichongding and Cycloxaprid were synthesized. Radiosynthesis of tritium-labeled Paichongding and Cycloxaprid was successfully achieved using $\mathrm{NaB}^{3} \mathrm{H}_{4}$ as the source of tritium. The use of radio-labeled compounds presents a promising approach for the detection and accurate analysis of compounds or products. Paichongding and Cycloxaprid were obtained with chemical purities of 98.7 and $98.4 \%$, and radiochemical purities of 97.3 and $98.6 \%$, respectively (Scheme 4). ${ }^{[33]}$ Furthermore, $\left[{ }^{14} \mathrm{C}\right]$ Paichongding was synthesized to exploit the stability and high sensitivity of carbon-14 under normal physiological conditions. From the facile and inexpensive $\left[{ }^{14} \mathrm{C}\right]$ nitromethane, $\left[{ }^{14} \mathrm{C}\right]$ Paichongding was readily prepared in five steps with chemical and radiochemical purities over $98 \%$ (Scheme 5). ${ }^{[34]}$ The acquisition of these radiotracers makes it convenient to study the MOA, metabolism, degradation and environmental behavior.

\section{Photostability of cis- Neonicotinoid}

The photostability of an insecticide is a vital factor to take into account for its field the molecule interacts with the receptor and facilitate the further molecular optimization. Neonicotinoid insecticides are selective agonists of insect nicotinic acetylcholine receptors (nAChRs). The modes of action of trans-configuration 
application. Although some nitromethylene neonicotinoids, such as 6-Cl-PMNI, exhibited high insecticidal activities and receptor binding affinity, ${ }^{[35]}$ 6-ClPMNI's lack of photostability ${ }^{[36]}$ limited its utility in crop protection. Therefore, it is essential to evaluate the stability of these nitromethylene cis-neonicotinoids. Paichongding is very stable in water, while IPPA152201 and Cycloxaprid are less stable with half-lives of $4 \mathrm{~h}$ and $60 \mathrm{~h}$, respectively. The photostability of cis-neonicotinoids decrease in the order Paichongding > Cycloxaprid > Imidacloprid > IPPA152201. The stability of Cycloxaprid is better than IPPA 152201 and imidacloprid. Paichongding has a much better photostability than imidacloprid. The degradation rate of two epimers of Paichongding varied greatly. The possible photodegradation pathway in aqueous solution under mercury lamp irradiation was proposed and 22 degradation products were identified, ${ }^{[37]}$ the main photodegradation product being 1-((6-chloropyridin3-yl)methyl)-7-methyl-5-propoxyhexahydroimidazo[1,2-a]pyridin-8 $(5 \mathrm{H})$-one (Scheme 6). All these results demonstrated that the introduction of tetrahydropyridine or other heterocycle to the nitromethylene scaffold could improve the photostability, making Paichongding and Cycloxaprid suitable for commercialization.

\section{Conclusion}

Cis-neonicotinoids, close relatives of trans-ones, have played an important role in the quest for the extension of the neonicotinoid alphabet in recent years. The systematic design and synthesis of an extensive series of cis-neonicotinoids has been performed to explore the influence of configuration on activities and subtle relationships between structures using fundamental chemistry principles. A large array of synthetic strategies to produce cisneonicotinoids has been developed to date and the excellence of the products has been verified. This perspective aimed to give an overview of recent research progress in our group. Like a growing baby, research on cis-neonicotinoids still surprises us with the most unexpected questions and observations. Looking into the future, the further identification of MOA, metabolism and environmental behavior based on radio-labeled compounds, and chiral separation of Paichongding and Cycloxaprid will be our next research emphasis. Although the cis-neonicotinoids have proved effective with their own merits, there still exist some problems such as stability and low lepidopteran activities. Therefore, the exploration of cis-neonicotinoids with novel scaffolds is a boundless frontier which is sure to yield surprises. Furthermore, we will try our best to promote the marketing of Paichongding, IPPA152201 and Cycloxaprid. We hope one day cis-neonicotinoids will find a place in the farmers' application instruments as an alternative for crop protection.

\section{Acknowledgments}

This work was financially supported by National Basic Research Program of China (973 Program, 2010CB126100), National High Technology Research and Development Program of China (863 Program, 2011AA10A207).

\section{Received: October 30, 2011}

[1] J. E. C. Jepson, L. A. Brown, D. B. Sattelle, Invert. Neurosci. 2006, 6, 33 .

[2] S. Kagabu, R. Ishihara, Y. Hieda, K. Nishimura, Y. Naruse, J. Agric. Food Chem. 2007, 55, 812.

[3] P. Jeschke, R. Nauen, M. Schindler, A. Elbert, $J$. Agric. Food Chem. 2011, 59, 2897.

[4] M. Tomizawa, J. E. Casida, Acc. Chem. Res. $\mathbf{2 0 0 9}, 42,260$

[5] M. Tomizawa, J. E. Casida, J. Agric. Food Chem. 2011, 59, 2825.

[6] S. Kagabu, J. Agric. Food Chem. 2011, 59, 2887.

[7] M. Tomizawa, J. E. Casida, J. Agric. Food Chem. 2011, 59, 2883.

[8] J. E. Casida, J. Agric. Food Chem. 2011, 59, 2923.

[9] I. Ohno, M. Tomizawa, K. A. Durkin, J. E Casida, S. Kagabu, J. Agric. Food Chem. 2009, $57,2436$.

[10] S. H. Thany, G. Lenaers, V. Raymond-Delpech, D. B. Sattelle, B. Lapied, Trends Pharmacol. Sci. 2007, 28, 14.

[11] I. Ohno, M. Tomizawaa, K. A. Durkin, J. E. Casida, S. Kagabu, Bioorg. Med. Chem. Lett. 2009, 19, 3449 .

[12] M. Tomizawa, S. Kagabu, J. E. Casia, J. Agric. Food Chem. 2011, 59, 2918

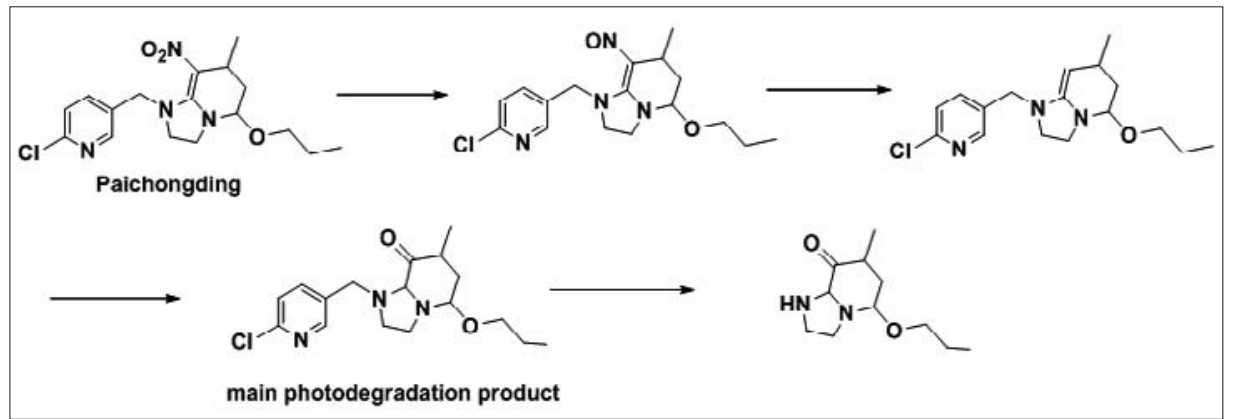

[13] Y. M. Zhu, M. R. Lose, G. B. Watson, T. C. Sparks, R. B. Rogers, J. X. Huang, B. C. Gerwick, J. M. Babcock, D. Kelley, V. B. Hegde, B. M. Nugent, J. M. Renga, I. Denholm, K. Gorman, G. J. DeBoer, J. Hasler, T. Meade, J. D. Thomas, J. Agric. Food Chem. 2011, 59, 2950.

[14] W. J. Qian, X. L. Shi, Pesticde Market News 2010, 23, 35.

[15] X. S. Shao P. W. Lee, X. Y. Xu, Z. W. Liu, Z. Li, X. H. Qian, J. Agric. Food Chem. 2011, 59 , 2943.

[16] X. S. Shao, W. W. Zhang, Y. Q. Peng, Z. Li, Z. Z. Tian, X. H. Qian, Bioorg. Med. Chem. Lett. 2008, 18,6513

[17] X. S. Shao, Z. Li, X. H. Qian, X. Y. Xu, J. Agric. Food Chem. 2009, 57, 951

[18] X. S. Shao, H. Fu, X. Y. Xu, X. L. Xu, Z. W. Liu, Z. Li X. H. Qian, J. Agric. Food Chem. 2010, $58,2696$.

[19] M. Tomizawa, S. Kagabu, I. Ohno, K. A. Durjin, J. E. Casida, J. Med. Chem. 2008, 51, 4213.

[20] I. Ohno, M. Tomizawa, K. A. Durkin, J. E Casida, S. Kagabu, J Agric. Food Chem. 2009, $57,2436$.

[21] M. Tomizawa, S. Kagabu, J. E. Casida, J Agric. Food Chem. 2011, 59, 2918.

[22] Y. L. Wang, J. G. Cheng, X. H. Qian, Z. Li, Bioorg. Med. Chem. 2007, 15, 2624

[23] W. W. Zhang, Y. B. Yang, W. D. Chen, L. Li, H. B. Zhai, Z. Li, J. Agric. Food Chem. 2010, 58, 2741

[24] X. S. Shao, Z. Li, X. H. Qian, X. Y. Xu, J. Agric. Food Chem. 2009, 57, 951

[25] Z. J. Ye, S. Xia, X. S. Shao, J. G. Cheng, Z. Li, X. H. Qian, J. Agric. Food Chem. 2011, 59, 10615.

[26] a) P. Jeschke, in 'Insecticides Design Using Advanced Technologies', Eds. I. Ishaaya, R. Nauen, A. R. Horowitz, Springer Verlag, Netherlands, 2007, pp 151-195; b) P. Maienfisch, F. Brandl, W. Kobel, A. Rindlisbacher, R. Senn, in 'Nicotinoid Insecticides and the Nicotinic Acetylcholine Receptor', Eds. I. Yamamoto, J. E. Casida, Springer-Verlag, Tokyo, 1999, pp 177-209; c) P. Maienfisch, M. Angst, F. Brandl, W. Fischer, D. Hofer, H. Kayser, W. Kobel, A. Rindlisbacher, R. Senn, A. Steinemann, H. Widmer, Pest Manag. Sci. 2001, 57, 906.

[27] X. S. Shao, X. L. Huang, Q. Shi, Z. Li, L. M Tao, G. H. Song, J. Heterocycl. Chem. 2011 accepted.

[28] T. T. Talley, M. Harel, R. E. Hibbs, Z. Radić, M Tomizawa, J. E. Casida, P. Taylor, Proc. Natl. Acad. Sci. USA 2008, 105, 7606.

[29] M. Tomizawa, D. Maltby, T. T. Talley, K. A. DurKin, K. F. Medzihradszky, A. L. Burlingame, P. Taylor, J. E. Casida, Proc. Natl. Acad. Sci. USA 2008, 105, 1728.

[30] I. Ohno, M. Tomizawa, K. A. Durkin, Y. Naruse, J. E. Casida, S. Kagabu, Chem. Res. Toxicol. 2009, 22, 476.

[31] X. Y. Xu, H. Bao, X. S. Shao, Y. X. Zhang, X. M. Yao, Z. W. Liu, Z. Li, Insect Molec. Biol. 2010, 10, 1

[32] X. S. Shao, H. Y. Liu, H. Bao, X. Y. Xu, Z. W. Liu, Z. Li, Insect Biochem. Mol. Biol. 2011, 41, 440.

[33] C. Li, X. Y. Xu, J. Y. Li, Q. F. Ye, Z. Li, J. Label. Compd. Radioparm. 2011, 54, 256.

[34] C. Li, X. Y. Xu, J. Y. Li, Q. F. Ye, Z. Li, J. Label. Compd. Radioparm. 2011, 54, 775 .

[35] S. Kagabu, H. Nishiwaki, K. Sato, M. Hibi, N. Yamaoka, Y. Nakagawa, Pest. Manag. Sci. 2002, 58,483

[36] S. Kagabu, S. Medej, Biosci., Biotechnol., Biochem. 1995, 59, 980.

[37] X. F. Zhao, X. S. Shao, Z. Y. Zou, X. Y. Xu, J. Agric. Food Chem. 2010, 58, 2746. 